Authors have nothing to disclose with regard to commercial support.

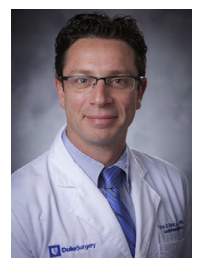

\section{REDO MITRAL SURGERY WITHOUT TRANSCATHETER OPTIONS: A CASE OF 7 CONSECUTIVE MITRAL OPERATIONS}

To the Editor:

We read with great interest the analysis of Ejiofor and colleagues $^{1}$ regarding conventional mitral reoperation in patients who could potentially be treated with a transcatheter device. They point out that the need for reoperation arose from prosthetic dysfunction, endocarditis, and perivalvular leak, in that order. Unfortunately, endocarditis and perivalvular leak may not be amenable to current transcatheter technology in all patients.

We would like to report a case of survival after 7 consecutive mitral operations in a single patient before the availability of transcatheter approaches. We think that this patient may illustrate some of the issues that could be avoided by availability of transcatheter technology, albeit at the risk of yet unknown outcomes with transcatheter devices.

Our patient was born in 1924 and died when he was 70 in 1994 after discharge from his seventh cardiac surgical operation. He was first operated on in 1979, when he was 55 years old. He had rheumatic aortic and mitral stenosis with left main and 3-vessel coronary disease. The patient underwent aortic and mitral valve replacements with porcine bioprostheses (models 2625 and 6625; Edwards Lifesciences, Irvine, Calif) along with double coronary bypass grafting with left internal thoracic artery to the left anterior descending coronary artery. Six years later, in 1985, he had a resternotomy for mitral and aortic valve re-replacements (models 1260 and 6120; Edwards Lifesciences) to correct mitral prosthetic dysfunction that had resulted in severe mitral regurgitation. Five months later, still in 1985, he underwent his third sternotomy for repair of a mitral perivalvular leak. One year later, in

The Editor welcomes submissions for possible publication in the Letters to the Editor section that consist of commentary on an article published in the Journal or other relevant issues. Authors should: • Include no more than 500 words of text, three authors, and five references. • Type with double-spacing. • See http://jtcs.ctsnetjournals.org/ misc/ifora.shtml for detailed submission instructions. • Submit the letter electronically via jtcvs.editorialmanager.com. Letters commenting on an article published in the JTCVS will be considered if they are received within 6 weeks of the time the article was published. Authors of the article being commented on will be given an opportunity of offer a timely response ( 2 weeks) to the letter. Authors of letters will be notified that the letter has been received. Unpublished letters cannot be returned.
1986, after treatment of endocarditis, vegetations developed on his mitral valve with severe perivalvular leak. He then underwent a fourth operation through a right thoracotomy for replacement of the mitral valve with another mechanical prosthesis (model 6120; Edwards Lifesciences). One month later, he underwent another right thoracotomy (fifth operation) for perivalvular leak of the mitral valve, which was treated by placement of a new mitral prosthesis (model 6120; Edwards Lifesciences). A year later, in 1987, he underwent his sixth operation, in which a perivalvular leak was repaired, through a left thoracotomy. The patient did well until 1994, when severe mitral regurgitation developed as a result of perivalvular leak. He then underwent a seventh operation through a resternotomy for re-replacement of the mitral valve (Carbomedics M-033; LivaNova PLC, London, UK). The patient was discharged and was doing well at home until 2 weeks postoperatively, when he died of an intracranial hemorrhage.

We are not aware of any reports of survival after 7 conventional or transcatheter cardiac valve procedures. Although transcatheter approaches to redo mitral surgery may have advantages in certain cases, endocarditis and perivalvular leak may still require conventional approaches for some redo mitral surgery.

Yaron D. Barac, $M D, P h D$

Walter Wolfe, $M D$

Donald D. Glower, MD

Division of Cardiothoracic Surgery

Duke University Medical Center

Durham, NC

\section{Reference}

1. Ejiofor JU, Hirji SA, Ramirez-Del Val FR, Norman AV, McGurk S, Aranki SF, et al. Outcomes of repeat mitral valve replacement in patients with prior mitral surgery: a benchmark for transcatheter approaches. J Thorac Cardiovasc Surg. 2018;156:619-27.e1.

https://doi.org/10.1016/j.jtcvs.2018.08.057

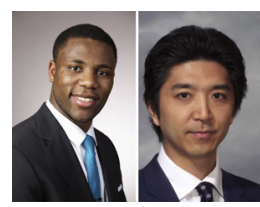

IN THE ERA OF

TRANSCATHETER

THERAPIES:

WILL COMPLEX

REOPERATIVE

CARDIAC

VALVE SURGERY GO

AWAY?

\section{Reply to the Editor:}

Barac and colleagues ${ }^{1}$ at Duke presented a successful case report of 7 consecutive mitral valve operations in a single patient. Although the patient ultimately died of intracranial bleeding weeks after the seventh operation, they are to be congratulated for such herculean efforts over a 15-year 
Tsuyoshi Kaneko is on the speaker's bureau for Edwards LifeSciences. The other author has nothing to disclose with regard to commercial support.

period. This patient first received a bioprosthetic mitral prosthesis at age 55 years for rheumatic mitral stenosis in 1979. Six years later, he underwent redo sternotomy for structural valve deterioration manifesting as severe mitral regurgitation. Over the ensuring decade, he underwent repeat mitral reoperations for paravalvular leaks (PVLs) $(\times 4)$ and prosthetic valve endocarditis $(\times 1)$.

As we read this report, the biggest question is how would we treat this problem if he were to be seen in 2018. New transcatheter approaches, including valve-in-valve transcatheter mitral valve replacement (ViV-TMVR), are now available. Would we treat these reoperative scenarios similarly? We will highlight several points based on our previously published article. ${ }^{2}$

The first is that if the patient presents with acute prosthetic valve endocarditis, the patient will not be amenable to transcatheter techniques. Active prosthetic valve endocarditis is considered a contraindication to transcatheter valve implantation. The basic tenant of endocarditis surgery is to remove all the prosthesis and debride infected tissue. There will always be room for open cardiac surgery for this etiology.

The second is the management of recurrent mitral PVL in the setting of poor, friable tissue from infection or calcification. Surgical repair or valve re-replacement remains the gold standard treatment modality for severe symptomatic mitral PVL ${ }^{3,4}$ (American College of Cardiology/American Heart Association Class I recommendation). However, percutaneous repair has emerged as a safe, effective alternative modality in high-risk patients. The current American College of Cardiology/American Heart Association guidelines give a Class IIa recommendation for percutaneous transcatheter repair of PVL in high-risk surgical patients such as this patient. ${ }^{3}$ Alkhouli and colleagues, ${ }^{4}$ from the Mayo Clinic, compared long-term outcomes of transcatheter and surgical management of mitral PVL. Their study showed that surgical treatment achieves higher rates of complete elimination of PVL $(95.5 \%$ vs $70.1 \%$, $P<.001)^{4}$ at the cost of higher morbidity/mortality, with mitral valve re-replacement required in $50 \%$ of cases.

The last point is the feasibility of ViV-TMVR. The multicenter global registry consisting of 32 centers reported the results of 64 patients who underwent TVMVR from 2012 to $2015 .^{5}$ Technical success was achievable in only $72 \%$ of patients, with $20 \%$ of patients having lethal procedural complications (left ventricular outflow tract obstruction [9.3\%], embolization [6.25\%], and perforation $[3.1 \%]) .^{5}$ It has been shown that the trans-septal approach provides superior outcomes compared with the transapical approach. ${ }^{6}$ Overall, ViV-TMVR is a technically challenging procedure, with left ventricular outflow obstruction being a disastrous complication that cannot be easily predicted on imaging. ${ }^{7}$ If the longterm valve durability and valve thrombosis risk are added, there are uncertainties whether this "minimally invasive" treatment will provide the same longevity as re-mitral valve replacement such as in this case.

At the end of the day, no matter how advanced the technology becomes, we will always have patients who will require surgical repair or replacement in the setting of valve failure. Surgeons will need to have the knowledge of how manage reoperative valve disease in their armamentarium, especially in the era of transcatheter therapies.

\section{Julius I. Ejiofor, $M D, M P H$ \\ Tsuyoshi Kaneko, $M D$ \\ Division of Cardiac Surgery \\ Brigham and Women's Hospital \\ Harvard Medical School \\ Boston, Mass}

\section{References}

1. Barac Y, Wolfe W, Glower D. Redo mitral surgery without transcatheter options: a case of 7 consecutive mitral operations. J Thorac Cardiovasc Surg. 2019;157: e129.

2. Ejiofor J, Hirji SA, Ramirez-Del Val F, Norman AV, McGurk S, Aranki SF, et al. Outcomes of repeat mitral valve replacement in patients with prior mitral surgery: a benchmark for transcatheter approaches. J Thorac Cardiovasc Surg. 2018;156: 619-27.e611.

3. Nishimura RA, Otto CM, Bonow RO, Carabello BA, Erwin JP III, Fleisher LA, et al. 2014 AHA/ACC guideline for the management of patients with valvular heart disease: a report of the American College of Cardiology/American Heart Association task force on practice guidelines. J Am Coll Cardiol. 2014;63:e57-185.

4. Alkhouli M, Rihal CS, Zack CJ, Eleid MF, Maor E, Sarraf M, et al. Transcatheter and surgical management of mitral paravalvular leak: long-term outcomes. JACC Cardiovasc Interv. 2017;10:1946-56.

5. Guerrero M, Dvir D, Himbert D, Urena M, Eleid M, Wang DD, et al. Transcatheter mitral valve replacement in native mitral valve disease with severe mitral annular calcification: results from the first multicenter global registry. JACC Cardiovasc Interv. 2016;9:1361-71.

6. Sengodan P, Sankaramangalam K, Banerjee K, Athappan G. Outcomes for percutaneous mitral valve-in-valves and mitral valve-in-rings in the transapical and transseptal access routes: a systematic review and pooled analysis. J Struc Heart Dis. 2018;2:214-20.

7. Blanke P, Naoum C, Dvir D, Bapat V, Ong K, Muller D, et al. Predicting LVOT obstruction in transcatheter mitral valve implantation: concept of the neo-LVOT. JACC Cardiovasc Imaging. 2017;10:482-5.

https://doi.org/10.1016/j.jtcvs.2018.11.033 